commonly shared vision of the future and to create new networks that enable a society to invest its science and technology resources more wisely, harness the beneficial effects of innovation, and ameliorate its risks. Yet foresight may provide only one way to create these benefits. As the book describes, the French government sponsors a small number of comprehensive foresight activities. By contrast, in the United States, many groups - from the independent but government-funded National Academy of Sciences to numerous non-profit organizations - offer visions of the future and build networks around them. Clearly, these approaches reflect different political and cultural contexts. But the different visions may provide different strengths and weaknesses, for instance, offering coherent actions versus resilience to surprise. The book helps frame questions about, for example, which approaches governments should choose, but it does not answer such questions.

To call this volume a handbook may be premature. The word connotes an easily consulted reference that provides quick answers to those engaged in an activity. As the editors note, technology foresight remains a diverse and experimental practice whose theoretical foundations are poorly understood and whose successes have not yet moved from the anecdotal to the empirically grounded. Much remains to be learned. Meanwhile, The Handbook of Technology Foresight provides an important survey of current knowledge that will help governments use foresight to navigate these tumultuous times. Robert Lempert is director of the RAND Frederick S. Pardee Center for Longer Range Global Policy and the Future Human Condition, 1776 Main Street, Santa Monica, California 90401, USA.

e-mail: lempert@rand.org

\title{
Potatoes and poverty
}

\section{Propitious Esculent: The Potato in \\ World History \\ by John Reader \\ William Heinemann: 2008. 315 pp. £18.99}

Propitious Esculent is not just a book about potatoes; it is also about poverty. The two are linked by history, and in this very readable account, anthropologist and journalist John Reader shows us how.

The cultivated potato, Solanum tuberosum, is one of around 1,500 species in the flowering plant genus Solanum, which also includes the tomato, aubergine and woody nightshade. There are some 190 species of wild potatoes, all found in the Andes - from these a single species has been domesticated and spread throughout the world. Those who only see potatoes in heaps at supermarkets may be surprised that the crop comes from a flowering plant and is one of South America's greatest contributions to the European diet. The United Nations Food and Agriculture Organization has declared 2008 the International Year of the Potato to raise awareness of its importance.

Botanically, the potato is a tuber, a swollen piece of underground stem where the plant stores starch. Wild potato plants and local 'primitive' varieties have tubers, but they are often small and oddly shaped, bearing little physical resemblance to those from cultivated varieties. Reader cites recent research on the taxonomy and domestication of these varied and complicated plants. Disappointingly, he does not incorporate recent work on the genetics of the potato and its relatives.

Nor does the book sufficiently discuss the genetic modification of potatoes for control of disease, an important issue for food poverty. Potatoes are one of the most expensive food crops in terms of pest and disease control. Reader cites the potato as the "world's most chemically dependent crop - with the global cost of fungicides standing at [US] $\$ 2$ billion per year". This astounding figure comes almost as a footnote at the end of a long chapter about the discovery of Phytophthora infestans, the agent of potato blight. The fungus, now associated with the devastation of world potato crops, was first discovered in grapevines. Reader's account of the disease, its discovery and its action is riveting, but potatoes are almost incidental to his story. Today, we easily see the connection between symptom and disease and can then search for causative agents: this was not so in the days when people thought microorganisms arose from spontaneous generation.

Reader does detail the development of blight-resistant potato varieties through the plant-breeding work of Redcliffe N. Salaman at the University of Cambridge, UK, in the early twentieth century. But he does not discuss more modern and controversial approaches. Disease control is being developed at the International Potato Center in Peru through 'true potato seed' potatoes - the crop is replanted using the seed from the original potato plant rather than vegetatively propagated from small pieces of tuber. These varieties have great promise for improving the gene pool for disease resistance, especially in the Andes, where genetically engineered potatoes cannot be used because of their potential for hybridizing with wild species.

Reader eloquently argues that social history is important to understand agricultural systems and sustainability. His engaging account of the potato's journey, from the Andes to Europe and beyond, starts and ends in local communities where the tuber is still central to daily life. Andean cultures cultivate potatoes in poorquality soils at high altitudes, mainly because

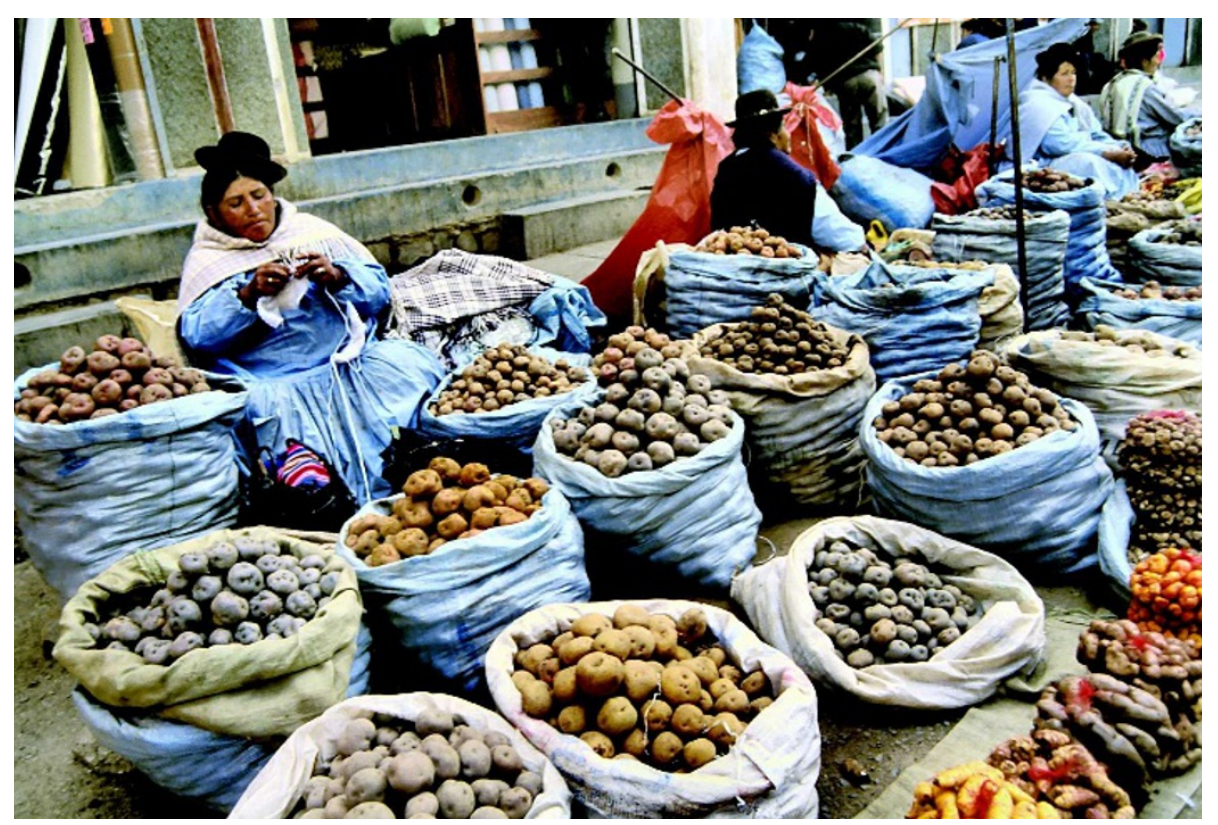

Mash production: potatoes are the world's most chemically dependent crop. 
they have been excluded from richer agricultural land by large landowners and commercial elites. Social factors also influenced the Irish potato famine of the mid-nineteenth century. Potatoes can feed a family well from a very small plot of land, improving offspring survival and thus driving population growth. Pushed onto marginal land by large landowners, Irish peasants nevertheless thrived by growing potatoes; they were desperately poor, but not starving. When the potato blight hit Ireland, the resultant starvation killed more than a million Irish people and led to the emigration of millions more.

In his account of the Irish famine, Reader offers the central message of the book. Eliminating extreme hunger and poverty is one of the United Nations' Millennium Development Goals, but the history of the potato shows us that truly eliminating poverty means much more than ensuring the security of food supplies and avoiding hunger; social equity is equally, if not more, important. Science on its own is no panacea for solving social ills.

Sandra Knapp is a plant taxonomist in the

Department of Botany, Natural History Museum, Cromwell Road, London SW7 5BD, UK.

e-mail: s.knapp@nhm.ac.uk

\section{Building from the environment}

\author{
Abundant Australia \\ The Australian Pavilion, 11th International \\ Architecture Exhibition, Venice \\ 14 September until 23 November 2008
}

Moving beyond the creation of iconic buildings, architects are looking to natural forms for inspiration by appropriating biological patterns, structures and mechanisms to engage with the landscape. At the 11th International Architecture Exhibition at this year's Venice Biennale, as part of Out There: Architecture Beyond Building, several countries will focus on science in their installations. Japan picks the theme of extreme landscapes for its pavilion, Denmark highlights ecology, Egypt chooses geometry and Spain looks to a future of 'paperless' design and construction.

The Australian pavilion displays 300 model exhibits from 180 architecture and design practices, and highlights the inspiration that can be found around us with designs inspired by the flora, fauna and environment of that whole continent.

The microscopic structures of scales on moth and butterfly wings inspired the duallayer, glazed facade on the Australian Museum's new Collections and Research Building, which will open in Sydney later this year. The cavity design of the panels will "insulate the building against extremes of temperature and humidity, and reduce traffic noise", says architectural practice Johnson Pilton Walker. Angled, dichroic glass within the panels seems to change colour as people walk past.

The Sydney-based French architect Frank Minnaërt asks how the

"We must conceive of architecture
in a different way from the Western
tradition based on a concept of
heroic domination of space."

functionality of biological membranes might be transposed into architecture, looking particularly at how organisms achieve maximum efficiency from minimal adaptation. His conceptual model Patternity comprises interacting

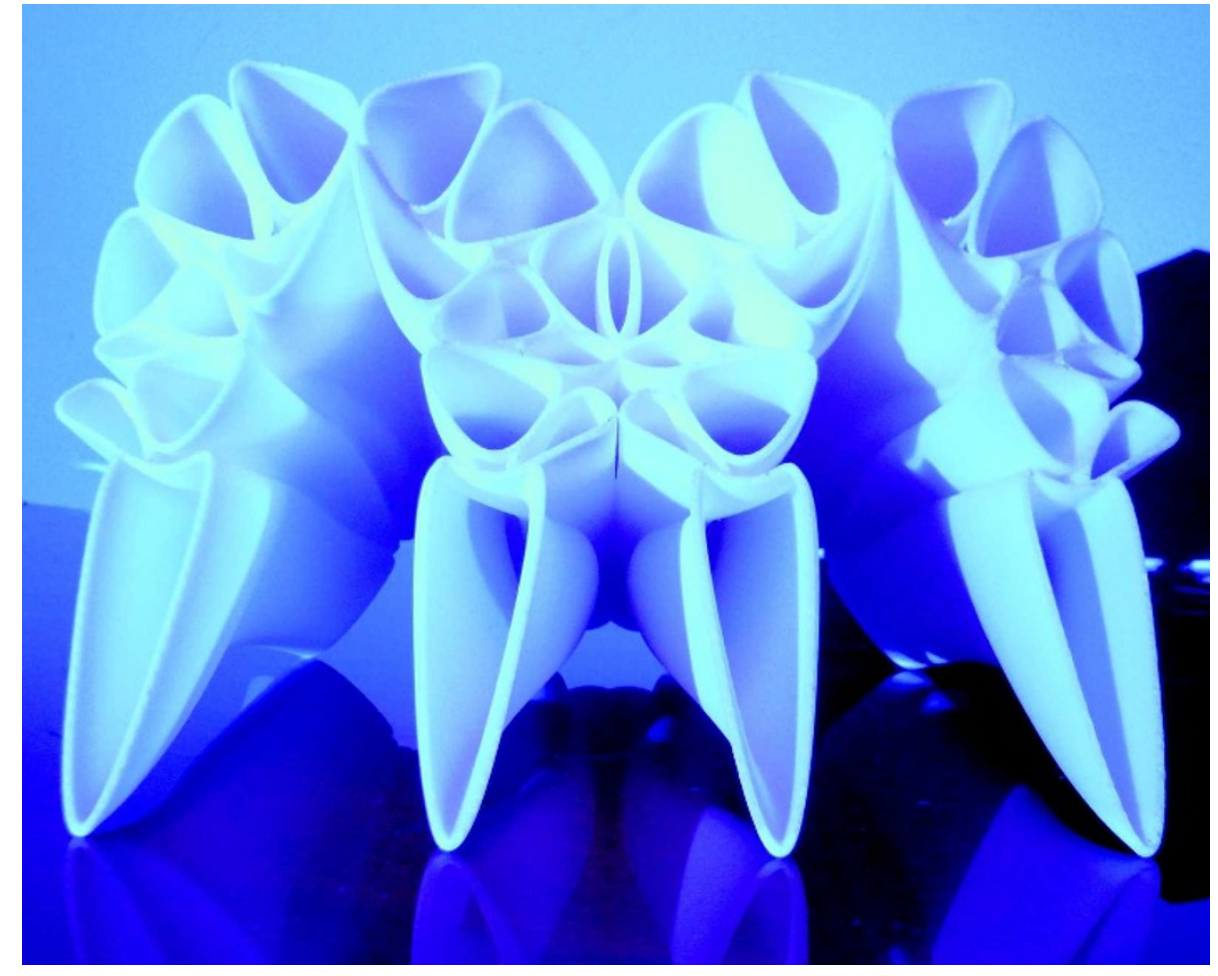

Frank Minnaërt's model Patternity highlights the potential of membranes to cool new buildings.

units through which selectively permeable thermal membranes, yet to be developed, might stabilize building temperatures throughout the year.

Some designers are inspired by natural processes, such as fire and erosion, that alter the Australian environment. "We must conceive of architecture in a different way from the Western tradition based on a concept of heroic domination of space," says John Nichols of Woodhead architects, who incorporated scorched timber into the newly opened Pinnacles Desert Discovery Centre in Western Australia.
Sunglasses for the Building, exhibited by spaceagency, is a light-hearted suggestion for providing shade for a beachside residential development under construction in Western Australia. "The screen detail was derived from images of nearby eroded limestone formations, and contributes to a unique sense of place," says practice director Michael Patroni.

These individual pavilions at the exhibition show that architectural responses to local environments can provide potent symbolism and functional solutions. As the exhibition's director Aaron Betsky states, "In a concrete sense, architecture is what allows us to be at home in the world."

Colin Martin is a writer based in London. e-mail:cmpubrel@aol.com 